\title{
ANALISIS RASIO SOLVABILITAS TERHADAP LAPORAN KEUANGAN UNTUK MENILAI TINGKAT KINERJA KEUANGAN PERUSAHAAN PT TIMAH Tbk
}

\author{
Ivo Arsela ${ }^{1}$, Endang Kartini Panggiarti ${ }^{2}$ \\ Program Studi D3 Akuntansi Universitas Tidar ${ }^{1}$ \\ email: ivoarsela221298@gmail.com
}

\begin{abstract}
ABSTRAK
Analisis rasio merupakan salah satu cara untuk menilai tingkat kinerja suatu perusahaan apakah keadaan keuangan perusahaan dalam kondisi yang baik atau tidak, dengan menganalisis laporan keuangan perusahaan. Tujuan dari penelitian ini yaitu mengetahui tingkat kinerja keuangan di PT. Timah Tbk yang dilihat dari sudut pandang analisis rasio solvabilitas. Metode analisis yang digunakan adalah analisis kuantitatif menggunakan rasio solvabilitas. Data dan informasi penelitian diperoleh dari Bursa Efek Indonesia periode pengamatan 2017, 2018, dan 2019. Rasio solvabilitas menunjukkan bahwa modal perusahaan PT. Timah Tbk mencukupi untuk dapat menjamin hutang yang diberikan oleh kreditor sehingga keadaan perusahaan dikatakan dalam keadaan sehat atau baik (solvable).
\end{abstract}

Kata Kunci: Laporan keuangan, rasio keuangan, kinerja perusahaan

\begin{abstract}
Ratio analysis is one way to assess the performance level of a company whether the company's financial condition is in good condition or not, by analyzing the company's financial statements. The purpose of this study is to determine the level of financial performance at PT. Timah Tbk seen from the point of view of solvency ratio analysis. The analytical method used is quantitative analysis using the solvency ratio. Research data and information were obtained from the Indonesia Stock Exchange for the 2017, 2018, and 2019 observation periods. The solvency ratio shows that the company capital of PT. Timah Tbk is sufficient to be able to guarantee debts given by creditors so that the condition of the company is said to be in a healthy or solvable condition.
\end{abstract}

\section{PENDAHULUAN}

\subsection{Latar Belakang}

Laporan keuangan merupakan alat yang penting untuk mengetahui posisi keuangan suatu perusahaan serta hasil-hasil yang telah dicapai oleh perusahaan tersebut. Alat analisis yang digunakan untuk mengetahui kinerja keuangan perusahaan antara lain menggunakan rasio keuangan. Bagi calon kreditor, laporan keuangan berguna untuk mengetahui jaminan yang disediakan oleh perusahaan atas hutang-hutangnya. Sedangkan untuk mengetahui kemampuan perusahaan dalam membayar bunga modal yang dipinjam tergantung pada keuntungan dimasa mendatang yang dapat dilihat pada laporan Laba Rugi Komprehensif. Untuk menutupi kekurangan akan kebutuhan dana, perusahaan dapat menggunakan sumber dana. Sumber dana dapat diperoleh dari modal sendiri dan pinjaman. Untuk mengetahui seberapa besarnya penggunaan masing-masing sumber dana, agar tidak membebani perusahaan, baik jangka pendek maupun jangka panjang maka dilakukan analisis rasio solvabilitas. Penelitian ini 
mempertimbangkan faktor eksternal dalam meneliti kinerja keuangan PT Timah Tbk. Disektor industri pertimahan, terdapat negara yang menghasilkan tambang timah terbesar dari tahun 2013 sampai 2020. PT Timah Tbk pada tahun 1991-1995 melakukan restrukturisasi yang mengakibatkan diberhentikannya ribuan karyawan, sekaligus dalam upaya menerjunkan saham mereka go international hal ini mungkin disebabkan PT Timah Tbk menyadari bahwa industri pertimahan merupakan salah satu industri yang selalu mengalami fluktuasi yang diakibatkan oleh perubahan harga timah dunia dan berfluktuasi nilai mata uang rupiah terhadap US Dollar (Best \& Guidelines, 2011). Faktor-faktor inilah yang membuat perusahaan besar ini menjadi menarik dijadikan sebagai objek penelitian untuk dikaji kinerjanya khususnya dilihat dari rasio keuangannya. Terkait dengan latar belakang tersebut maka kami melalukan penelitian dengan judul "Analisis Rasio Solvabilitas Terhadap Laporan Keuangan Untuk Menilai Tingkat Kinerja Perusahaan PT Timah Tbk"

\subsection{Identifikasi Masalah}

Rumusan masalah dalam penelitian ini, berdasarkan latar belakang diatas adalah "Bagaimanakah kemampuan PT Timah Tbk dari tahun 2017 sampai dengan 2019 dalam memenuhi liabilitas keuangan perusahaan dengan menggunakan analisis rasio solvabilitas?"

\subsection{Tujuan Penelitian}

Tujuan dari penelitian ini adalah untuk mengetahui kemampuan PT Timah Tbk dalam memenuhi liabilitas keuangan perusahaan dengan menggunakan analisis rasio solvabilitas periode tahun 2017-2019.

\section{KAJIAN PUSTAKA}

\subsection{Laporan Keuangan}

Laporan keuangan merupakan suatu informasi yang menggambarkan kondisi keuangan perusahaan pada suatu periode tertentu. Menurut Munawir Fahmi (2011:2) laporan keuangan merupakan alat yang sangat penting untuk memperoleh informasi sehubungan dengan posisi keuangan dan hasil-hasil yang telah dicapai oleh perusahaan yang bersangkutan. Dengan begitu laporan keuangan diharapkan akan membantu para pengguna (users) untuk membuat keputusan ekonomi yang bersifat finansial. Dari pendapat diatas dapat disimpulkan bahwa laporan keuangan adalah suatu alat yang sangat penting untuk mendapatkan informasi kondisi keuangan perusahaan pada suatu periode, yang dapat digunakan untuk mengambil keputusan dan menggambarkan kinerja suatu perusahaan.

\subsection{Rasio Solvabilitas dan Jenis Rasio Solvabilitas}

Sumber - sumber dana secara garis besar dapat diperoleh dari modal sendiri dan pinjaman (bank atau lembaga pinjaman lainnya). Bank dapat memilih dana dari salah satu sumber tersebut atau kombinasi keduanya. Setiap sumber dana memiliki kelebihan dan kekurangan masing - masing. Disamping itu dengan menggunakan modal sendiri tidak ada beban untuk membayar angsuran termasuk bunga dan biaya lainnya. Sebaliknya kekurangan modal sendiri sebagai sumber dana yaitu jumlahnya yang relatif terbatas, terutama saat menjatuhkan dana yang relatif besar.

Rasio solvabilitas (Laverage) merupakan rasio yang digunakan untuk mengukur sejauh mana aktiva atau aset bank dibiayai oleh utang. Artinya berapa besar beban utang yang ditanggung bank dibandingkan dengan asetnya. Dalam arti luas dikatakan bahwa rasio ini digunakan untuk mengukur kemampuan bank untuk membayar seluruh kewajibannya, baik jangka pendek maupun jangka panjang apabila bank dibubarkan (pailit). Semakin tinggi rasio solvabilitas maka semakin tinggi pula risiko kerugian yang dihadapi, tetapi juga ada kesempatan memperoleh keuntungan yang besar. Sebaliknya jika bank memiliki solvabilitas yang rendah tentu mempunyai risiko kerugian yang lebih kecil. Dampak ini juga 
mengakibatkan rendahnya tingkat hasil pengembalian (return) pada aset perekonomian tinggi. Kesimpulannya dengan rasio solvabilitas, perusahaan akan mengetahui beberapa hal yang berkaitan dengan penggunaan modal sendiri dan modal pinjaman serta mengetahui rasio kemampuan bank untuk memenuhi kewajibannya.

\section{METODE PENELITIAN}

Penelitian ini menggunakan metode penelitian kuantitatif, yaitu penelitian yang mendeskripsikan keadaan yang menjadi fokus dalam penelitian berdasarkan data berupa angka yang telah dikumpulkan (Widayat, 2004). Sumber data yang diambil untuk melakukan penelitian ini adalah data sekunder yang diperoleh dari laporan keuangan perusahaan dan ringkasan kinerja keuangan perusahaan yang diperoleh dari situs resmi Bursa Efek Indonesia (BEI) dan situs resmi perusahaan yang bersangkutan.

Penelitian ini mengunakan metode analisa horizontal dengan mengadakan perbandingan laporan keuangan untuk beberapa periode sehingga akan diketahui perkembangannya. Dalam melakukan analisis horizontal, sebuah akun laporan keuangan tahun berjalan dibandingkan dengan akun yang sama pada periode sebelumnya. Kemudian dari hasil analisis tersebut kemudian akan terlihat perkembangan perusahaan dari periode sebelumnya dengan periode berjalan.

\section{HASIL DAN PEMBAHASAN}

\subsection{Analisa Rasio Solvabilitas}

Perhitung analisis rasio solvabilitas pada PT Timah Tbk untuk periode 2017 sampai dengan 2019 adalah sebagai berikut:

\section{Total debt to equity ratio}

Rasio ini merupakan rasio yang digunakan untuk menilai utang dengan ekuitas pemilik. Rasio ini dicari dengan cara membandingkan antara seluru utang termasuk utang lancar dengan seluruh ekuitas. Dengan kata lain rasio ini berfungsi untuk mengetahui setiap rupiah modal sendiri yang dijadikan untuk jaminan utang. Bagi perusahaan semakin rendahnya rasio ini maka semakin tinggi tingkat pendanaan yang disediakan pemilik dan semakin besar batas pengamanan bagi peminjam jika terjadi kerugian atau penyusutan terhadap nilai aktiva. Rasio ini juga menunjukkan kelayakan dan risiko keuangan bank. Formula untuk menghitung total debt to equity ratio adalah:

a. Total debt to equity ratio tahun bulan Desember 2017 adalah:

$2017 \frac{\text { Total Liabilities }}{\text { Total Equity }}=\frac{5.814 .816}{6.061 .493}=95,93 \%$

b. Total debt to equity ratio tahun bulan Desember 2018 adalah:

$2018 \frac{\text { Total Liabilities }}{\text { Total Equity }}=\frac{9.072 .333}{6.148 .352}=147,56 \%$

c. Total debt to equity ratio tahun bulan Desember 2019 adalah:

$2019 \frac{\text { Total Liabilities }}{\text { Total Equity }}=\frac{15.102 .873}{5.258 .405}=287,21 \%$


Dari perhitungan Total debt to equity ratio dapat diambil kesimpulan sebagai berikut:

Tabel 1. Total Debt to Equity Ratio

\begin{tabular}{|l|l|}
\hline Tahun & Total debt to equity ratio \\
\hline 2017 & $95,93 \%$ \\
\hline 2018 & $147,56 \%$ \\
\hline 2019 & $287,21 \%$ \\
\hline
\end{tabular}

PT Timah Tbk pada tahun 2017 mempunyai Total debt to equity ratio yaitu sebesar 95,93\% naik menjadi $147,56 \%$ itu berarti Rp 1,47 dari setiap rupiah ekuitas sendiri menjadi jaminan untuk keseluruhan liabilitasnya. Pada tahun 2018 total ekuities sebesar Rp 6.148 .352 turun menjadi Rp 5.258.405 pada tahun 2019.

\section{Total Debt to Asset Ratio}

Rasio ini merupakan rasio utang yang digunakan untuk mengukur perbandingan antara total utang dengan total aktiva. Dengan kata lain seberapa besar aktiva bank dibiayai oleh utang atau seberapa besar utang bank berpengaruh terhadap pengelolaan aktiva. Semakin tinggi rasio ini maka pendanaan dengan utang semakin banyak, maka semakin sulit bagi bank untuk memperoleh tambahan pinjaman karena dikhawatirkan perusahaan tidak mampu menutupi utang - utangnya dengan aktiva yang dimiliki. Sebaliknya rendahnya rasio ini maka semakin kecil bank yang dibiayai oleh utang.

a. Total Debt to Asset Ratio tahun bulan Desember 2017 adalah:

$2017 \frac{\text { Total Liabilities }}{\text { Total Asset }}=\frac{5.814 .816}{11.876 .309}=48,96 \%$

b. Total Debt to Asset Ratio tahun bulan Desember 2018 adalah:

$2018 \frac{\text { Total Liabilities }}{\text { Total Asset }}=\frac{9.072 .333}{15.220 .685}=59,61 \%$

c. Total Debt to Asset Ratio tahun bulan Desember 2019 adalah:

$2019 \frac{\text { Total Liabilities }}{\text { Total Asset }}=\frac{15.102 .873}{20.361 .278}=74,17 \%$

Dari perhitungan Total Debt to Asset Ratio diatas dapat diambil kesimpulan sebagai berikut : PT Timah Tbk pada tahun 2017 mempunyai Total Debt to Asset Ratio yaitu sebesar 48,96\% berarti $\mathrm{Rp} 0,48$ dari setiap rupiah ekuitas sendiri menjadi jaminan untuk keseluruhan liabilitasnya. Pada tahun 2017 total aset sebesar Rp 11.876.309 naik menjadi Rp 15.220.685 pada tahun 2018. Aset naik kembali pada tahun 2019 menjadi Rp 20.361.278.

\section{Long Term Debt to Equity Ratio}

Rasio ini merupakan rasio yang digunakan untuk menilai utang jangka panjang

yang dimiliki bank terhadap ekuitas pemilik. Rasio ini dengan membandingkan antara jumlah seluru hutang jangka panjang yang dimiliki bank dengan ekuitas pemilik. Dengan kata lain rasio ini berfungsi untuk melihat jaminan modal sendiri terhadap utang jangka panjang yang dimiliki oleh perusahaan. 
Untuk menghitung long-term debt to equity ratio digunakan rumus dan fungsi sebagai berikut:

a. Long Term Debt to Equity Ratio tahun 2017 adalah:

$2017 \frac{\text { Long Term Debt }}{\text { Total Equity }}=\frac{2.412 .290}{6.061 .493}=39,80 \%$

b. Long Term Debt to Equity Ratio tahun 2018 adalah:

$2018 \frac{\text { Long Term Debt }}{\text { Total Equity }}=\frac{2.436 .908}{6.148 .352}=39,64 \%$

c. Long Term Debt to Equity Ratio tahun 2019 adalah:

$2019 \frac{\text { Long Term Debt }}{\text { Total Equity }}=\frac{3.144 .688}{5.258 .405}=59,80 \%$

Dari perhitungan long term debt to equity ratio diatas dapat diambil kesimpulan sebagai berikut:

PT Timah Tbk pada tahun 2017 mempunyai long term debt to equity ratio yaitu sebesar 39,80\% turun menjadi 39,64\% yang berarti Rp 0,39 dari setiap rupiah ekuitas sendiri menjadi jaminan liabilitas jangka panjang. Pada tahun 2018 Total equity sebesar Rp 6.148 .352 mengalami penurunan tahun 2019 menjadi Rp 5.258.405.

\section{Tangible Assets Debt Coverage}

Rasio ini digunakan untuk mengukur besar asset tetap tangible yang digunakan untuk menjamin setiap rupiah liabilitas jangka panjang. Untuk menghitung tangible assets debt coverage digunakan rumus dan fungsi sebagai berikut:

a. Tangible Assets Debt Coverage tahun 2017 adalah:

$2017 \frac{\text { Fixed Asset }}{\text { Long Term Debt }}=\frac{4.879 .343}{2.412 .290}=202,27 \%$

b. Tangible Assets Debt Coverage tahun 2018 adalah:

2018 Fixed Asset $=\frac{6.204 .028}{2.436 .908}=254,59 \%$

c. Tangible Assets Debt Coverage tahun 2019 adalah:

$2019 \frac{\text { Fixed Asset }}{\text { Long Term Debt }}=\frac{8.054 .223}{3.144 .688}=256,12 \%$

Dari perhitungan tangible assets debt coverage diatas dapat diambil kesimpulan sebagai berikut:

PT Timah Tbk pada tahun 2017 mengalami kenaikan dari tiap tahunnya, tangible assets debt coverage yaitu sebesar 202,27\% naik menjadi $254,59 \%$ yang berarti Rp2,54 dari setiap rupiah liabilitas jangka panjang menjadi jaminan asset tangible. 


\section{SIMPULAN DAN SARAN}

\subsection{Kesimpulan}

Berdasarkan pembahasan tersebut maka dapat disimpulkan bahwa secara umum kondisi keuangan sudah cukup baik.

1) Debt to total asset ratio dari tahun 2017 sampai 2019 menunjukkan nilai yang kurang baik karena assets yang dimiliki perusahaan kurang mampu membayar utang perusahaan serta nilainya selalu bertambah setiap tahun. DTAR (Debt to Asset Ratio) tahun 2017 sebesar 48,96\% sedangkan tahun 2018 mengalami peningkatan menjadi sebesar 59,61\% untuk tahun 2019 diperoleh sebesar $74,17 \%$. Semakin tinggi rasio ini maka pendanaan dengan utang semakin banyak, maka semakin sulit bagi bank untuk memperoleh tambahan pinjaman karena dikhawatirkan perusahaan tidak mampu menutupi utang - utangnya dengan aktiva yang dimiliki.

2) Dilihat dari debt to equity ratio pada PT. Timah terlalu tinggi karena tingginya nilai utang yang dimiliki perusahaan dibandingkan modal. Pada tahun 2017 DER (Debt to Equity Ratio) diperoleh sebesar 95,93\% sedangkan tahun 2018 mengalami kenaikan sebesar 147,56\% dan tahun 2019 diperoleh sebesar $287,21 \%$. Kenaikan rasio setiap tahunnya menunjukan bahwa perusahaan kurang baik dalam modal membayar utang.

3) Dilihat dari long term debt to equity ratio dari tahun 2017 sampai 2019 menunjukkan bahwa perusahaan mengalami penurunan sebesar 39,80\% turun menjadi 39,64\%. Pada tahun 2018 Total equity sebesar Rp 6.148.352 mengalami penurunan tahun 2019 menjadi Rp 5.258.405.

4) Dari perhitungan tangible assets debt coverage diatas dapat diambil kesimpulan bahwa PT Timah Tbk pada tahun 2017 mengalami kenaikan di tiap tahunnya, tangible assets debt coverage yaitu sebesar 202,27\% naik menjadi $254,59 \%$ yang berarti Rp2,54 dari setiap rupiah liabilitas jangka panjang menjadi jaminan asset tangible.

\subsection{Saran}

Adapun sarannya adalah sebagai berikut:

1. Dalam meningkatkan rasio solvabilitas, maka perusahaan sebaiknya mengurangi jumlah liabilitasnya, baik liabilitas dalam jangka pendek maupun dalam jangka panjang dan selanjutnya dapat meningkatkan asset perusahaan agar perusahaan tidak kesulitan dalam membayar liabilitasnya.

2. Manajemen PT. Timah Tbk sebaiknya tetap memperhatikan penggunaan liabilitas dalam ekuitas yang digunakan oleh perusahaan, sehingga risiko yang dihadapi perusahaan lebih kecil dan kreditor tetap memberikan pinjamannya. 


\section{DAFTAR PUSTAKA}

PT. Timah Tbk Annual Report PT Timah Tbk tahun 2017 diakses pada tanggal 12 Desember 2020 jam 16:40.

PT. Timah Tbk Annual Report PT Timah Tbk tahun 2018 diakses pada tanggal 12 Desember 2020 jam 16:46.

PT. Timah Tbk Annual Report PT Timah Tbk tahun 2019 diakses pada tanggal 12 Desember 2020 jam 16:50.

Fahmi, Irham. (2011).Analisis Laporan Keuangan. Alfabeta:Bandung.

Munawir. (2010). Analisis Laporan Keuangan. Liberty: Yogyakarta.

Widayat, Amirullah. (2004). Metode Penelitian Pemasaran. Malang: CV Cahaya Press.

Novianti, Sylviana Indah. (2013). Penilaian Kesehatan Keuangan Perusahaan Konstruksi di Indonesia. Salatiga: Universitas Kristen Satya Wacana

Riyanti, B., \& Sudarmawanti, E. (2019). Pengaruh Manajemen Laba terhadap Earning Response Coefisient dengan Kualitas Audit sebagai Variabel Pemoderasi. Jurnal Ecodunamika, 2(2).

Tamosang, M. (2012). Analisis Perbandingan Kinerja Keuangan Perusahaan Yang Bergerak Dalam Bidang Real Estate dan Property. Proceeding for Call Paper Pekan Ilmiah Dosen FEB UKSW.

Hanafi dan Halim.(2014).Analisis Laporan Keuangan. UUP STIM YKPN: Yogyakarta.

Rahardjo, Budi. (2003). Laporan Keuangan Perusahaan: Membaca, Memahami, dan Menganalisis. Yogyakarta: Gadjah Mada University Press 